\title{
Adaptive, integrated water management designs and probabilistic modelling for mine waste facility closure and restoration
}

H Garrick Golder Associates (UK) Ltd, UK

F Stewart Dundee Precious Metals Krumovgrad, Bulgaria

E Hayes Golder Associates (UK) Ltd, UK

M Goode Golder Associates (UK) Ltd, UK

G Digges La Touche Golder Associates (UK) Ltd, UK

\begin{abstract}
Closed Mine Waste Facilities (MWFs), both tailings and waste rock facilities, represent a potential hazard to the downgradient surface water and groundwater environment. Adaptive, integrated engineering designs at mine sites with short-term life-of-mine resources necessarily mean that closure should be factored into designs and mitigation measures very early in the project lifecycle. Not least, as key decision makers can see the finish line even before the first ore has been shipped. Also, there is emphasis on the importance of having a mechanism for providing a demonstrable analysis, which increases the confidence of the designer/owner, the regulatory authorities, and the public, that the solution is providing environmental protection.
\end{abstract}

The assessment of the long-term risks such facilities pose to the water environment is an important issue for mine closure, particularly when the potential for an impact on the water environment has been identified, necessitating the need to make financial provision for aftercare costs. In addition to the need for financial provision during aftercare, European and international regulatory frameworks require mitigation of potential impacts on the water environment in the long-term, necessitating assessments to account for long-term cover/cap and liner performance as well as changes in climate. This paper presents a case study describing the use of a series of modelling approaches, including probabilistic modelling, to evaluate design performance and risk associated with an Integrated Mine Waste Facility (IMWF) at Dundee Precious Metals Krumovgrad's (DPMK's) proposed mine site in Krumovgrad, Bulgaria. The case study illustrates the application of probabilistic modelling involving the use of probabilistic risk assessment to appraise differing closure and remediation strategies for the IMWF at the design stage based on available environmental data. In the case study presented, probabilistic modelling was successfully applied to quantify the nature of the risk to groundwater and surface water in closure, and the degree of amelioration afforded by differing management techniques (placement of a basal liner, installation of a groundwater capture system for a defined period, and capping of the site in closure). The ultimate decision that the site should move forward with a groundwater capture scheme to provide containment for the site during operation and early post-closure was supported by impact assessments demonstrating that the tailings and waste rock source would not pose a long-term risk to groundwater and surface water in closure.

\section{Introduction}

The method applied in assessing the long-term performance of Mine Waste Facilities (MWFs) in respect to the water environment must consider the quality of any direct discharges to surface water, and also the impact of any discharges to ground which may ultimately impact groundwater resources, and therefore surface waters receiving groundwater discharge. The design process must provide appropriate mitigation 
with regard to impacts on the water environment in all phases of the mine lifecycle, including closure and post-closure (e.g. in Europe, as required by Directive 2006/21/EC (EU 2006b)), such that impact assessment must be undertaken at an early stage in the mine planning and permitting process, when limited data is available. Both operational and closure designs will often evolve in parallel with the impact assessment to arrive at an optimal design, and therefore modelling approaches must be flexible and responsive to design change. An assessment method that is risk-based allows operators, investors, regulators and the public to understand the degree of uncertainty associated with environmental predictions, and the risk drivers for design decisions.

The process of physical and geochemical characterisation of mine wastes which is now industry standard (described in e.g. EC (2009)) provides a robust basis for the understanding of the contaminant source term associated with the waste. Geochemical characterisation and modelling is established as the best assessment methodology for the prediction of 'contact water' quality within the MWF throughout the mine lifecycle. However, this characterisation process must be undertaken based on realistic predictions of infiltration rates to the waste material, and ultimately provides an input, rather than an answer, to the understanding of risk to the water environment. The Global Acid Rock Drainage (GARD) Guide (INAP 2009) provides guidance on characterisation and impact assessment process: an illustration of the assessment process 'road map' is reproduced in Figure 1. In particular, this approach illustrates the application of a tiered approach to the assessment, where predictive modelling is required when characterisation indicates that a potential concern exists. Whilst the GARD guide describes the predictive modelling process, it does not provide detailed guidance on modelling approaches in surface water systems and the geosphere.

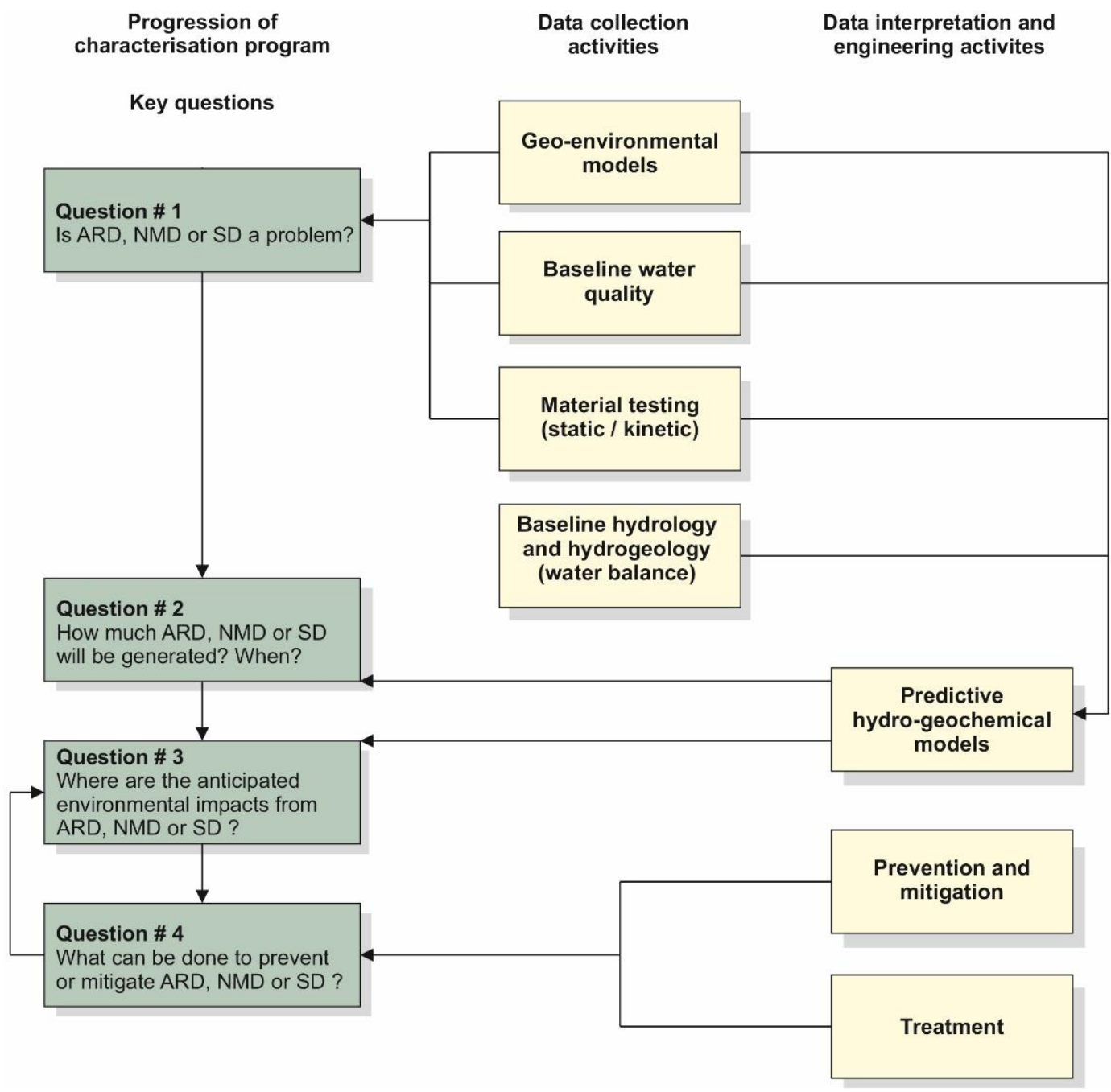

Figure 1 Characterisation process road map, after INAP (2009). ARD: acid rock drainage; NMD: neutral mine drainage, SD: saline drainage 
Typically, assessments of impact on the water environment will consider pathways associated with direct discharges to surface water, and migration in groundwater. A successful overarching assessment methodology must:

- Produce a robust model that is representative of the physical system, based on the best available information and appropriate assumptions.

- Predict the quantity of water entering the waste mass throughout the mine lifecycle.

- Predict water quality within the facility not only during operation, but in closure.

- Predict the interaction between 'contact waters' within the facility and the wider mine (surface) water system and, therefore, concentrations at the point of direct discharge to surface waters.

- Define the quantity and quality of 'contact waters' discharged to ground underlying the facility during operation and closure, and therefore, contaminant loads over the mine lifecycle.

- Predict the interaction between 'contact waters' discharged to ground, and the geosphere, and therefore the ultimate potential impact on groundwater, and through groundwater, surface water receptors.

Furthermore, in order to assess performance over the mine lifecycle these approaches must take account of closure engineering and the evolution of engineering controls over time (i.e. degradation of engineered components, and cessation of active controls).

The range of options available for the assessment of groundwater and surface water impacts arising from mining activities is ever-increasing, as is the technical complexity of the assessments which can be completed. However, few tools are able to simultaneously represent all of the system components outlined above, and modelling costs escalate rapidly with the use of sophisticated modelling tools.

Beyond source characterisation and source modelling, typical approaches to assess lifecycle impacts on the wider water environment are summarised below, ordered in generally increasing complexity and data intensity:

- Mass balance models of contaminant movement in mine water systems, the geosphere, lakes and rivers.

- Analytical models (in isolation or combined to form analytical element models) of mixing, surface water and groundwater flow and contaminant transport.

- Geochemical models of compartment mixing (in mine system waters and surface waters), and reactive transport in the geosphere.

- Numerical saturated groundwater flow and contaminant transport modelling in one, two or three dimensions using porous medium or dense fracture network (DFN) models.

- Numerical unsaturated (vadose) and saturated flow and contaminant transport modelling, in one, two or three dimensions.

- Numerical modelling of surface water flow and advective transport (computational fluid dynamics).

- Coupled numerical models incorporating multiple elements such as geochemistry, geomechanics and flow in multiple media.

In addition to being technically complex, costly and with significant data requirements, many numerical and geochemical modelling methods also rely on deterministic modelling and are not readily adapted to assess uncertainty in input data. Mixing and dilution in the mine water system is subject to a great deal of uncertainty as a result of climatic variation. Movement in the geosphere is subject to considerable uncertainty due to limitations in the characterisation of the geosphere and the hydraulic performance of the MWF. 
The use of probabilistic (stochastic) calculation approaches using Monte Carlo simulation applied to simple mass balance and analytical hydrogeological/contaminant transport models to understand the interaction of the MWF with the water environment is a powerful tool in understanding both the degree and likelihood of possible impacts. Probabilistic methods combined with analytical models have the potential to incorporate the evaluation of uncertainty, whilst providing a less data-intense and technically complex alternative to numerical models. The use of a probabilistic dynamic simulation modelling platform for decision analysis, such as GoldSim ${ }^{\mathrm{TM}}$ (GoldSim Technology Group 2014), to combine analytical calculations into an analytical element model is hugely flexible in allowing development of a system model which can represent evolution of the mine and mine engineering, the role of uncertainty in environmental risk and focus on an efficient 'top down' modelling approach. As GoldSim is a modelling platform, rather than a defined system model, models are unconstrained and can readily be adapted in response to design change.

This paper describes the use of a series of modelling approaches, including probabilistic modelling in a dynamic simulation modelling platform of the mine water system and groundwater impacts, to evaluate design performance and risk to the groundwater environment during operation and closure for a proposed IMWF at Dundee Precious Metals Krumovgrad's (DPMK's) proposed mine site in Krumovgrad, Bulgaria. Modelling was used to support decision making during the design, and to assess environmental impacts in operation and closure from the final facility.

\section{Application of probabilistic modelling to environmental risk assessment}

Probabilistic modelling is used to address the uncertainty that is inherent in the majority of the input parameters required in groundwater and surface water impact assessment. Probabilistic modelling allows the prediction of outcomes regarding receptor impacts, but also the likelihood of occurrence of those outcomes. As such, the probabilistic model informs the risk posed to the water environment by the facility. Input parameters which are not known precisely, due to limited sampling or heterogeneity (e.g. in physical and hydraulic properties of geological units or the nature of the mine waste materials), can be represented through stochastic inputs which capture the understanding of the probable value of the parameter at the scale of interest. Probabilistic, dynamic simulation tools use stochastic methods to randomly sample statistical distributions of input parameters and undertake model calculations with selected input values. This process of selection is repeated many times in a method known as Monte Carlo analysis, to produce a set of output values that can be expressed statistically to describe the likelihood of certain outcomes (Figure 2).

\section{Input variables}

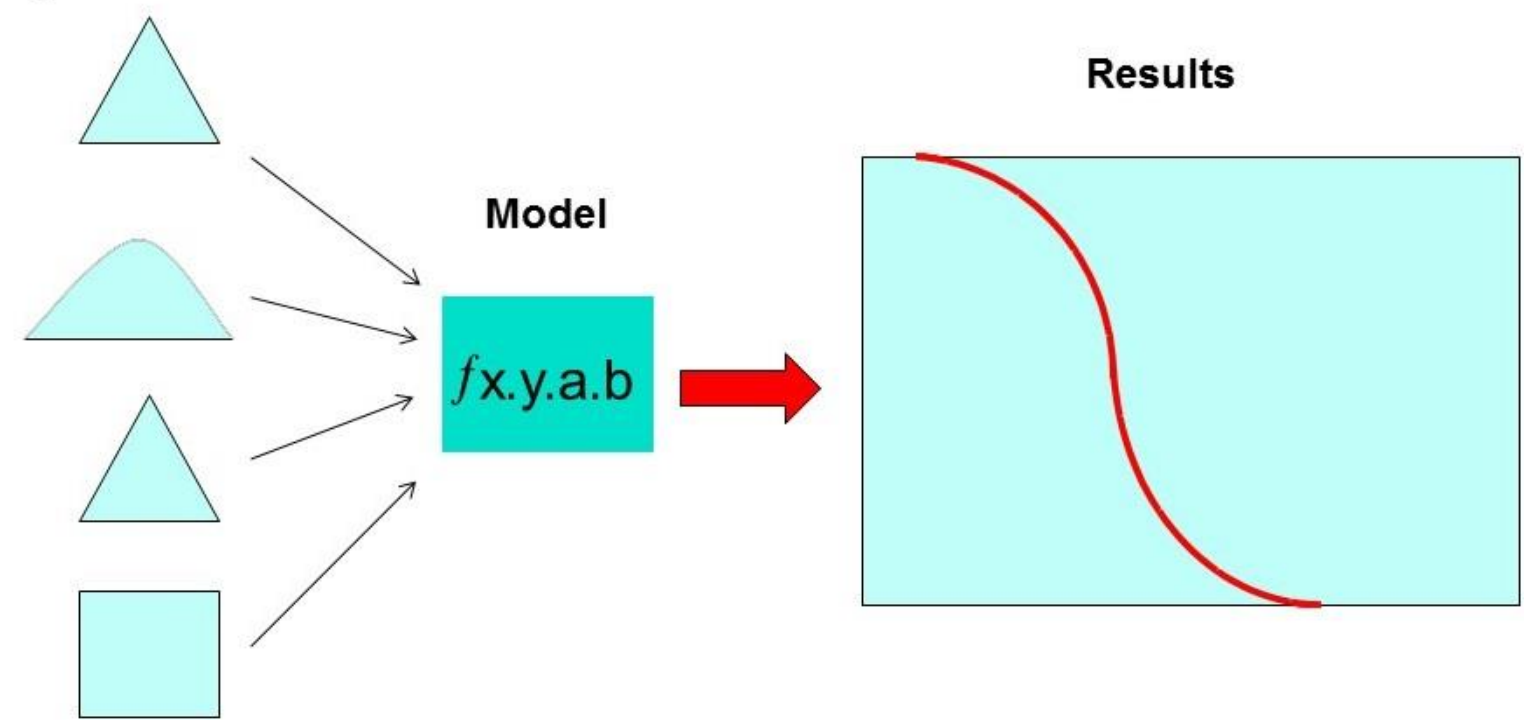

Figure 2 The components of a probabilistic simulation 
The likely range of results can be presented based on probability of occurrence and an understanding of the sensitivity of the parameters incorporated in the model, which provides information in a quantitative format that can aid both regulatory and management decisions. The application of probabilistic simulation approaches to groundwater impact assessment has been central to groundwater protection in the UK over the past 20 years, as described in NGCLC (1999).

There are three components to any environmental risk assessment, the source, in this case the mine waste, the pathways linking the source with any receptors, and the receptors, entities which may be harmed by the contamination. In the case of the water environment, these receptors consist of groundwater and surface water bodies such as rivers and streams. If any of the components of the source-pathway-receptor system are absent from a site setting, negligible risk will be posed to the groundwater and surface water environment.

The basis for the impact assessment is, therefore, in developing a conceptual model, through characterisation of the hydrological and hydrogeological setting of the site, of the source-pathway-receptor linkages which require consideration. A probabilistic analytical model is then constructed as a basis for the risk assessment process, and site characterisation data used to parameterise the model. For groundwater assessments, the analytical element model developed will typically incorporate a one-dimensional contaminant transport model representing advection and attenuation through dilution, dispersion, sorption, precipitation, and biodegradation in a specific migration pathway. However, in GoldSim, multiple models can readily be combined with the contaminant transport model, for example representing evolution in infiltration and leakage to or from the facility, evolution in source term concentration and evolution in engineered containment. Surface water models using this type of approach will typically be compartment models, which may represent different processes (such as dilution, evaporation, mixing, precipitation, sorption to sediments, volatilisation, or biodegradation) that will influence water quality evolution in each compartment.

\section{Case study: Krumovgrad integrated mine waste facility}

DPMK's Krumovgrad Gold Project is a mine project at detailed design stage located in southern Bulgaria. The immediate site geometry and setting, and groundwater flow components under natural conditions are illustrated in Figure 3 ('before'). The site comprises two steep valleys on the flank of a ridge, which together form a single watershed. The valleys lie approximately perpendicular to an upland river at the foot of the catchment. Streams in the valleys are ephemeral, and groundwater contribution to the streams fluctuates through the year with fluctuating groundwater level. The setting of the IMWF is such that, once the full facility is constructed, the catchment will receive little recharge to groundwater through areas of natural ground to provide dilution to any release from the IMWF. The catchment forming the site discharges to an upland river located directly to the east.

The mine design incorporates an innovative IMWF design which will receive both waste rock and thickened tailings: waste rock is used to provide the structural basis of the facility, with a honey-comb structure of tailings cells, filling the valley (Figure 3, 'after'). The facility design incorporates a basal drainage system, capturing flow to the base of the two main valleys and directing water to contact water capture sumps at the toe of the facility. The objective of the design is to reduce the footprint both of the overall mine site and of the waste facilities, in comparison to two separate facilities, and to allow the IMWF to be sited in an area of very steep, rocky terrain. The waste rock will provide strength for design stability and allow infiltrating rainwater and tailings drain-down water from consolidation to drain freely. However, the IMWF is sited in a steep valley in close proximity to a sensitive alluvial aquifer used for drinking water supply and an upland river, rendering the site setting highly sensitive in respect to the potential risks posed to surface water and groundwater quality. 


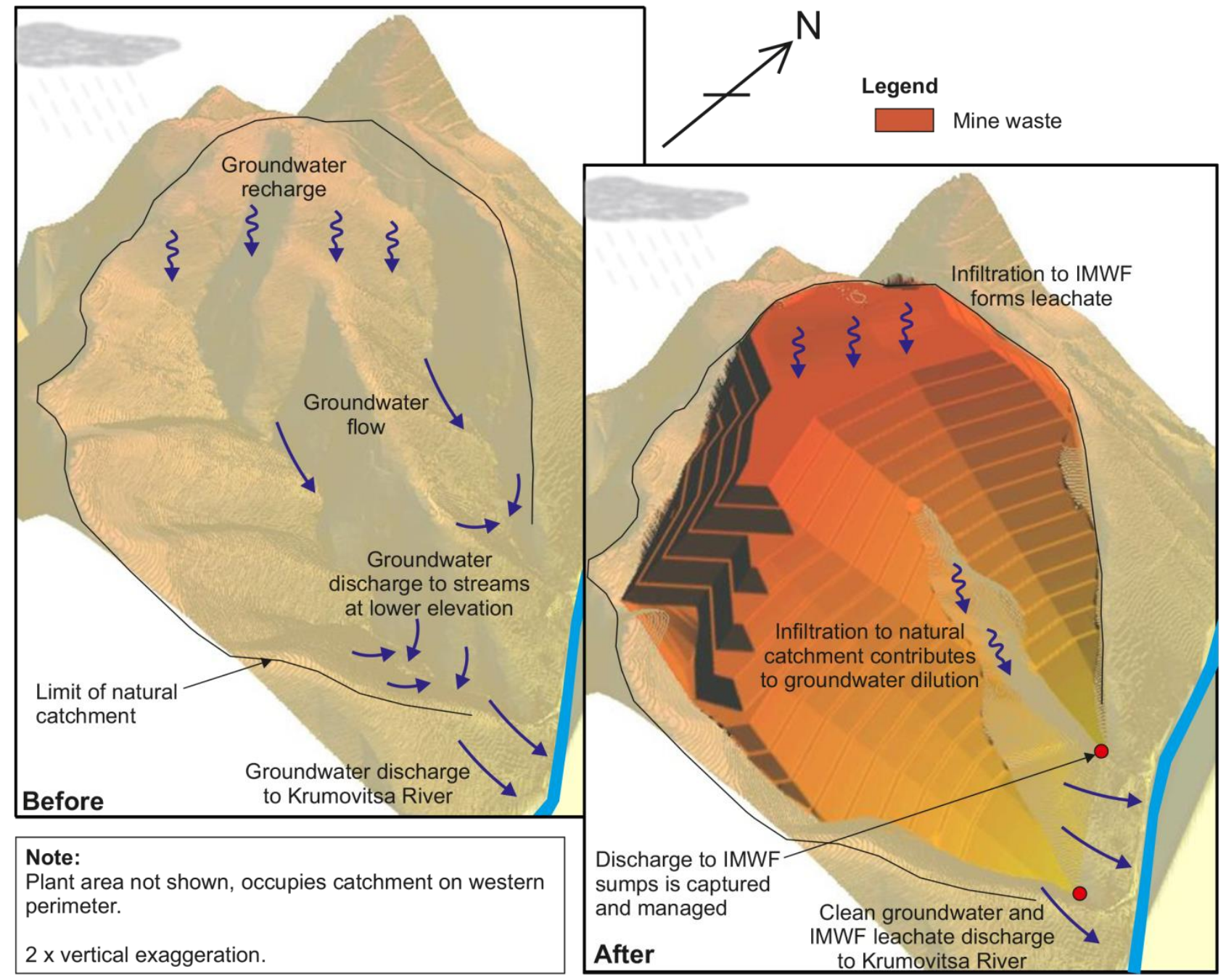

Figure 3 IMWF setting and geometry, and groundwater flow components before and after filling, in the unlined case

Tight regulations in Europe (Directives 2006/11/EC, 2006/118/EC and 2000/60/EC (EU 2000, 2006a, 2006c)) and Bulgaria of the release of contaminants to groundwater or surface water are such that the facility cannot be permitted to affect groundwater or surface water in the vicinity of the facility during operation or in the long-term. In the case of the Krumovgrad Project, this was also a condition of the legal Environmental Impact Assessment Resolution (which preceded the introduction of EU law in Bulgaria) which governs the parameters within which the site can be developed.

Initially, due to the legislative constraints, complete basal lining of the facility was proposed to mitigate water impacts at an early stage in the facility design. However, due to concerns over the constructability of the liner, its reliability and effectiveness, the basis of this decision was subsequently re-evaluated (with differing design alternatives) through impact assessment in order to evaluate the risks to the water environment in operation, closure and post-closure. This decision was primarily driven by concerns over the comparatively high risk, despite the selection of appropriate materials and detailed liner design, of damage to the structural integrity of the liner on the very steep rocky terrain of the facility.

A programme of groundwater, surface water and waste characterisation was completed. This was followed by an impact assessment to look at the risk to groundwater and surface water in operation and closure based on a range of design alternatives for the facility. The assessment considered three design alternatives: an unlined facility, a facility with a basal liner, and an unlined facility with a groundwater capture system operating for the first 30 years of operation. 
The geometry of the facility represented was similar in all three scenarios. In all three scenarios, the facility is progressively restored during operations and in closure with a vegetated soil cover to promote runoff and evaporation, affecting the rate of infiltration. Captured drainage discharges to contact water sumps at the facility toe (Figure 3). During operation, water entering the sumps will be returned to the mine water management system and treated (if required) prior to discharge. Variations in design between the proposed scenarios are as follows:

- In the lined scenario, a bituminous geomembrane is present underlying waste mass and drains are present both above the liner to capture contact water and beneath the liner to carry groundwater discharge with both streams discharging to the toe sumps.

- In the unlined scenario, drains are laid in gravel surrounds following the main natural drainage routes, capturing both groundwater discharge and contact water: the hydraulics in the unlined scenario is illustrated in Figure 3 ('after').

- In the groundwater capture scenario, drains are as in the unlined case, but the scenario considered a grout curtain $30 \mathrm{~m}$ in depth, with capture wells sited along the upgradient (facility) side of the grout wall at $25 \mathrm{~m}$ spacing. The optimisation of the groundwater capture system design was the subject of separate study. Groundwater from the capture system will be returned to the mine water system and treated (if required) prior to discharge.

The impact assessment adopted a tiered risk assessment approach. Contaminants of potential concern were identified at the characterisation stage based on typical mine waste characteristics, groundwater and surface water quality, humidity cell test eluate concentrations and the process design. These contaminants were assessed in the source term modelling. Those contaminants identified as potential risk drivers based on their concentration in the modelled source term were then carried forward to the quantitative groundwater and surface water impact assessment (contaminant transport modelling). Finally, based on the results of the preliminary risk modelling, certain contaminants (arsenic and phosphate) were identified as key risk drivers, partially due to uncertainty over the potential for sorption of these species. Site specific partition coefficient were determined for these species and included in the final impact assessment.

\subsection{Characterisation}

A hydrogeological and geochemical characterisation programme was completed as part of the environmental baseline studies and design studies for the facility. The programme of works included:

- Static and kinetic geochemical testing of waste rock and pilot tailings samples.

- Geotechnical characterisation of tailings, including development of soil moisture characteristic curves.

- Drilling of boreholes, hydraulic testing (packer testing and surface infiltration tests) and installation of groundwater monitoring wells.

- Outcrop fracture mapping.

- Collection of groundwater level, groundwater quality and surface water quality data from both the site area and wider region over a period of more than two years.

- Spring survey of the IMWF catchment.

- Partition coefficient testing with respect to key contaminants (arsenic and phosphate) identified through risk screening preliminary scoping assessments.

Hydrogeological field data was used to develop a hydrogeological conceptual model of the locality of the IMWF. The site is underlain by thin soils (on average $0.3 \mathrm{~m}$ in thickness) overlying fractured gneiss and granitic bedrocks. Flow in the bedrock is anticipated to occur primarily through secondary fracture porosity. An alluvial (sand and gravel) aquifer follows the river at the foot of the catchment, overlain in some areas 
by alluvial silts and clays. Groundwater levels in the bedrock within the IMWF footprint are strongly controlled by topography and groundwater flows predominantly eastward, with the direction of slope, toward the adjacent river. Groundwater along the two valley lines is close to surface, recorded at less than $1 \mathrm{~m}$ below ground in the upper portion of the catchment, and slightly artesian at the foot of the catchment. In the interfluves, groundwater is up to $25 \mathrm{~m}$ below ground level in the upper parts of the catchment. Investigation data indicated that the surface soil/rock interface was between one and two orders of magnitude more permeable than the underlying bedrock. Bedrock hydraulic conductivity showed high spatial variability, as would be expected in a fractured system. Whilst a consistent weathered zone was not observed, average hydraulic conductivity was observed to decrease with depth in the bedrock (Figure 4). Groundwater in the alluvial aquifer at the foot of the facility is assumed to flow northward, approximately perpendicular to the orientation of the facility, flowing parallel to the adjacent river.

\section{Hydraulic conductivity distribution} ( $5 \%$ ile, geometric mean, $95 \%$ ile)

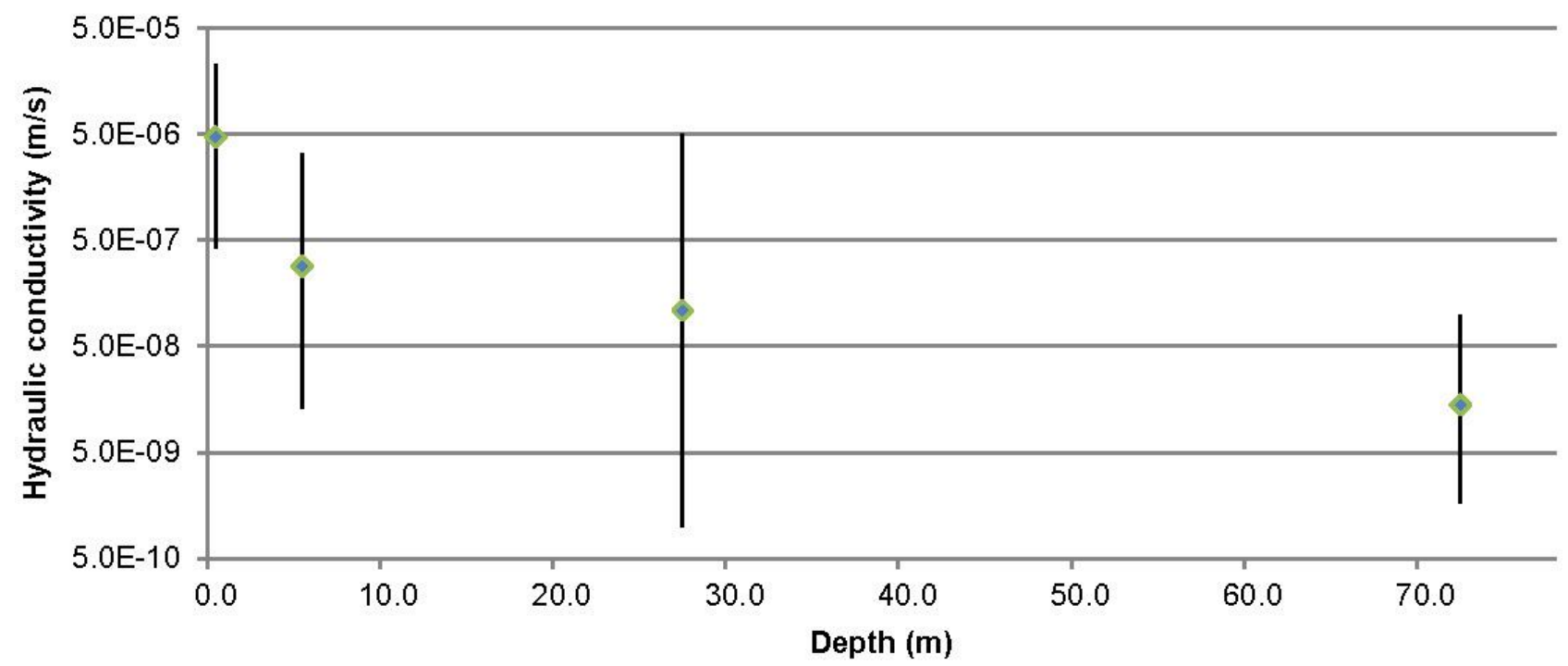

Figure 4 Bedrock hydraulic conductivity from packer testing and infiltration tests

\subsection{IMWF hydraulics}

As an input to the design and impact assessment, modelling was undertaken of water movement through and from the IWMF during operation and closure. This modelling comprised:

- A daily timestep soil moisture balance to assess the influence of precipitation, evapotranspiration and runoff and to evaluate infiltration through the restored slopes and platform area using the method described in Rushton (2003).

- Two-dimensional unsaturated flow modelling using Geostudio SEEP/W 2012 (GEO-SLOPE 2013) of a representative (longitudinal) section of the IMWF to assess the relative contribution of water to the basal drainage system and to ground in the unlined scenario with and without a groundwater capture system at the toe of the facility.

- Analytical calculations of leakage (primarily through defects) in the bituminous geomembrane underlying the facility in the lined scenario, using the method for a single geomembrane proposed in Giroud and Bonaparte (1989) and based on high quality construction quality assurance (CQA) during placement.

Soil water balance modelling indicates that infiltration to the restored slopes was in the range of $50 \mathrm{~mm} / \mathrm{yr}$ to $60 \mathrm{~mm} / \mathrm{yr}$, whilst infiltration to platforms was estimated to be between $140 \mathrm{~mm} / \mathrm{yr}$ to $180 \mathrm{~mm} / \mathrm{yr}$. These values were slightly adjusted in subsequent calibration of the numerical flow model. 
Development of the facility is planned to commence from the toe of the slope. Numerical modelling indicated that, due to the occurrence of groundwater discharge in the lower slope area, discharge to ground from early cells would be returned to the basal drainage system in local groundwater flow, and there would be no net release to groundwater downgradient of the facility. As the facility expands upslope, the degree of natural hydraulic containment reduces. Based on extrapolation of the results of two-dimensional flow modelling over the full facility extent, the annual average rate of leakage to groundwater from the facility in the unlined state at its final extent without groundwater capture was calculated to be between $0.51 \mathrm{~L} / \mathrm{s}$ and $0.55 \mathrm{~L} / \mathrm{s}$, with remaining infiltration passing to the basal drainage system and sumps. Modelling indicated that groundwater capture at the base of the slope would affect rates of leakage from the unlined facility: reduction in the water table elevation and change in flow lines as a result of pumping resulted in greater leakage to ground and lower discharge to the basal drainage system in the groundwater capture scenario. Based on the final design of the groundwater capture system, the leakage from the facility was estimated to range between zero in the early development stages and $0.8 \mathrm{~L} / \mathrm{s}$ at the final facility extent.

The predicted leakage through the base of the lined facility during operations, based on a defect occurrence rate of 3 defects per ha (Giroud 2001), ranged between $0.06 \mathrm{~L} / \mathrm{s}$ during operation and $0.05 \mathrm{~L} / \mathrm{s}$ in closure, approximately an order of magnitude lower than the leakage in the unlined scenario. The calculated leakage rate is highly sensitive to the assumed defect rate; however, the defect rate assumed is higher than reported for similar (bituminous geomembrane) liners installed with strict CQA in place and is considered highly conservative. The lining system, which was ultimately excluded from the design, and evaluation of the geotechnical suitability and feasibility of a full lining system was the subject of a separate options evaluation and design study.

\subsection{Source term modelling}

Static geochemical tests identified that the waste rock and tailings materials typically had a low sulphur content: more than half of the samples contained no detectable sulphide sulphur $(<0.1 \%)$, while the samples that did contain measurable sulphide sulphur (up to $1.5 \%$ ) generally also had abundant acid neutralising potential (NP). No samples were classified as Potentially Acid Generating (PAG) according to internationally accepted criteria (MEND 2009; INAP 2009). Results of kinetic testing were consistent with static tests results: following 20 weeks of testing, humidity cell leachates were neutral to alkaline with low to below detection limit concentrations of metals. Because the samples are crushed and rinsed more frequently than they would be in reality, the humidity cell procedure is considered an accelerated weathering test and a useful tool to assess long-term reactivity (i.e. for ARD/metal leaching potential) in a reasonable timeframe. The humidity cell tests therefore provided an early indication that the long-term environmental risks posed by the IMWF would be low. However, 'first flush' and early time eluate concentrations reported in the tests exceeded water quality standards (drinking water standards, environmental quality standards for surface water) with respect to iron, arsenic, copper, lead, and phosphate. Mercury, cadmium and selenium were not detected in humidity cell eluates or in surface water or groundwater during monitoring. These substances were therefore concluded at this stage to be absent from the source term.

In addition to the release of contaminants associated with geochemical reactions in the tailings and waste rock, evaluation of the planned operations concluded that the following contaminants were also of potential concern in water released from the IMWF:

- Ammoniacal nitrogen and nitrate arising from blasting residues.

- Potassium amyl xanthate (PAX) in tailings discharged from the mill flotation process, and carbon disulphide, the product of degradation of PAX.

Modelling was undertaken to further refine the quality of 'contact waters' in the IMWF (Golder Associates 2014). Two modelling approaches were used to characterise the quality of 'leachate' potentially discharged to ground from the IMWF and water quality in the collector sumps at the toe of the facility. To assess the 
concentration of long-term discharge from the IMWF, a mass-loading geochemical model with mixing was undertaken in a geochemical thermodynamic computer program (PHREEQC Version 3.0.6: Parkhurst and Appelo (2013)) based on the 'steady state' late time (week 20) humidity cell data. The concentration of discharge during operations was assessed through development of a mass balance model coupled to the stochastic site-wide water balance model. Both the site-wide water balance and mass balance were developed for the purposes of design of the site's water management system; however, this study also provided valuable input to the impact assessment.

Geochemical modelling of the long-term closure state concluded that water quality in contact water leached from the base of the site and discharged to sumps in the long-term post-closure would be similar to baseline surface water quality. The concentrations of contaminants of potential concern in post-closure were predicted to be below relevant water quality standards, with the exception of arsenic and antimony: these substances were below detection in the eluate from kinetic tests (attenuation by adsorption to iron oxides may be expected at the alkaline $\mathrm{pH}$ ), but the detection limits were such that they had the potential to be present above water quality standards in future contact waters based on the detection limit concentration (Golder Associates 2014).

Mass balance modelling of the operational state indicated that contact waters released during this phase could potentially exceed relevant water quality standards with respect to antimony, arsenic, fluoride, iron, lead, nickel, phosphorus, sulphate, ammonium and nitrate. Retardation during transport in the subsurface is such that contaminants released during the operational phase may continue to affect the water environment for many years (or centuries) after closure. Therefore, the presence of contaminants above water quality standards during operation poses a risk to the water environment in both operation and closure. On the basis of the outcome of the source term assessment, it was concluded that further quantitative (pre-construction) assessment of the risk to groundwater and surface water over the mine lifecycle was required to understand potential impacts associated with release during the operational phase. A detailed risk assessment was therefore undertaken, as described below.

\subsection{Groundwater and surface water impact assessment}

Following the studies described above, the following pathway was identified as requiring detailed risk assessment as part of the groundwater and surface impact assessment:

- Basal leakage from the facility and advection in groundwater, entering the alluvial aquifer and subsequently discharging to the adjacent river.

In addition to the above, the risk of uncontrolled release from on-site water storages, and water quality in the event of a release, was assessed as part of the (stochastic) operational site-wide water balance and associated mass balance undertaken using GoldSim.

A probabilistic dynamic simulation model was developed to represent:

- The phased development of the IMWF within the groundwater and surface water catchment.

- Evolution of the source term released to groundwater (quality and quantity) through operation, closure and post-closure.

- Advection, dispersion, dilution, sorption and biodegradation (of ammonium) in groundwater in gneiss/granitic bedrock underlying the facility.

- The influence of operation of the groundwater capture system for a period of 30 years at the toe of the facility.

- Dilution of contaminants in ground water within the alluvial aquifer adjacent to the facility.

- Dilution in surface water following discharge of affected groundwater to the river. 
Dilution calculations considered flow in the river under low flow conditions. All of the groundwater discharged from the facility footprint was assumed to be discharged to the alluvial aquifer and river within the facility footprint. Modelling of groundwater flow in the bedrock was undertaken using a one-dimensional cell network. In the simulation, as the conceptual model does not include any groundwater inflow from outside the local surface water catchment, flow in the aquifer is defined by the volume of infiltration over time (based on a fluid mass balance), rather than the hydraulic properties of the aquifer and hydraulic gradient. In comparison, flow in the receiving alluvial aquifer was calculated based on the hydraulic gradient and measured hydraulic conductivity.

The model considered water quality impacts for a 1,000 year period from the start of mine operations. Stochastic inputs were used to represent: the permeability of the alluvial aquifer, flow in the river in proximity to the site and downstream, partition coefficients of sorbed contaminants, porosity of the bedrock aquifer, and some elements of source concentration. As the contaminant transport modelling brought together results of deterministic models for some aspects of the system under consideration, not all parameters could be represented stochastically, though sensitivity analyses undertaken on deterministic model components were used to feed into stochastic modelling inputs. The simulation was run for 501 realisations in order to define the 95th percentile confidence bound on reported values. A number of conservative assumptions are incorporated in the modelling, particularly in the representation of the operational source term and assumptions regarding flow in the receiving waters (assumed to be at low flow).

The conceptual model represented in the contaminant transport assessment in the scenario in which the facility is unlined with groundwater capture is illustrated in Figure 5.

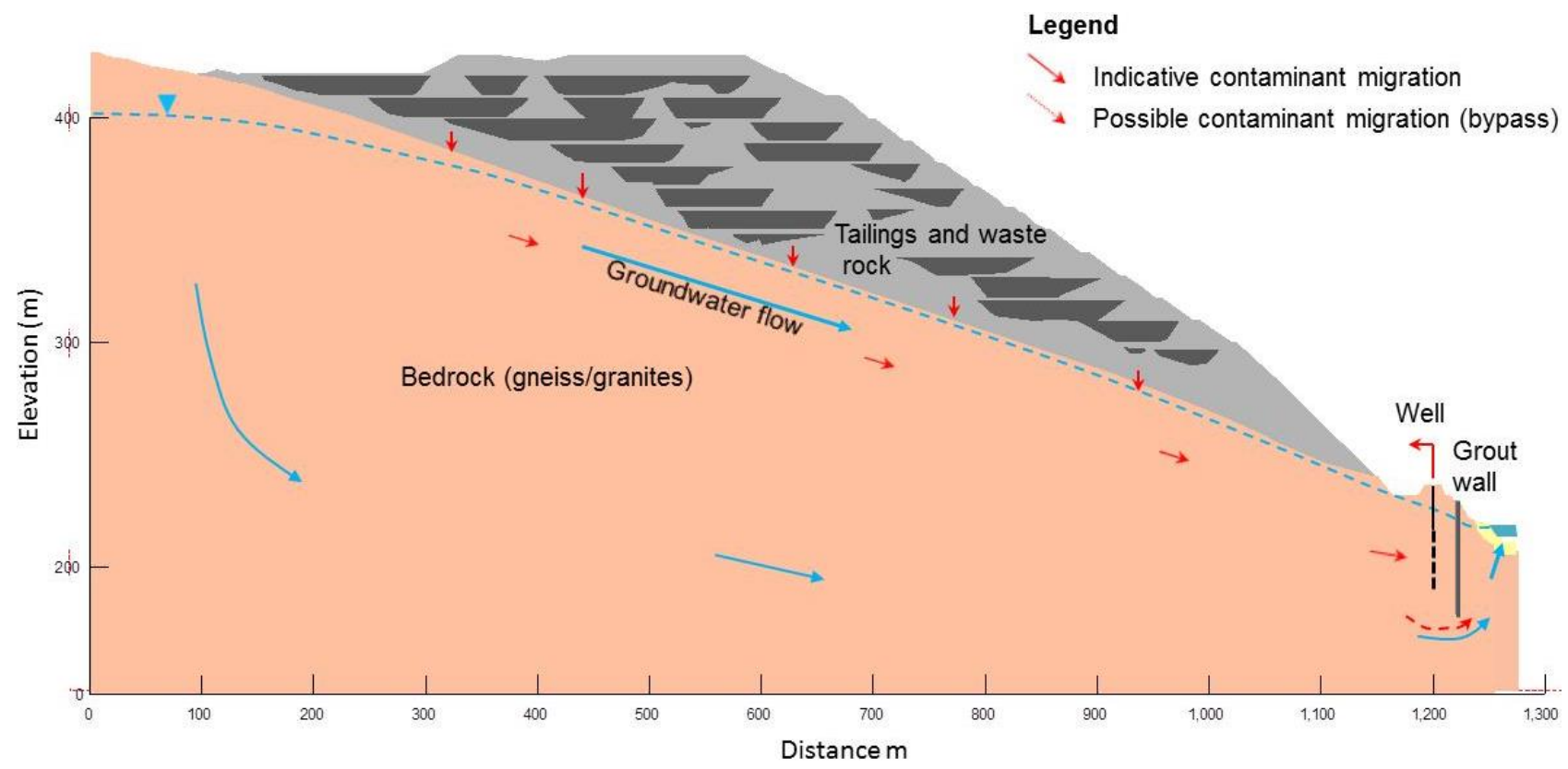

Figure 5 Conceptual model of contaminant migration in groundwater, unlined IMWF with groundwater capture

As described previously, three scenarios were assessed:

- An unlined facility with no engineered containment.

- A fully lined facility with a bituminous geomembrane basal liner.

- An unlined facility with a groundwater capture system operating for a period of 30 years from the commencement of operations. 


\subsection{Decision analysis}

In the decision process, the 95th percentile result was selected as the appropriate threshold for assessment of risks to groundwater and surface water: i.e. an adverse result was considered acceptable if its probability of occurrence was less than $5 \%$.

The results of stochastic contaminant transport modelling for the three scenarios indicated that:

- In lined scenario, groundwater quality at the point of discharge to the alluvial aquifer and in the receiving river would remain below applicable water quality standards over the modelled 1,000 year lifecycle period with respect to contaminants of potential concern.

- In the unlined scenario with no engineered containment, arsenic may exceed the water quality standards in groundwater at the point of discharge to the alluvial aquifer in the long-term (centuries after closure) based on the 95th percentile result. This is considered to represent an unacceptable risk of adverse impact on groundwater quality.

- In the groundwater capture scenario, groundwater quality at the point of discharge to the alluvial aquifer and in the receiving river would remain below applicable water quality standards over the modelled period.

- In all cases, no statistically discernible change in water quality in the river immediately downstream of the site would occur following mixing of groundwater discharge over an assumed diffuse discharge zone.

The modelling study also allowed prediction of the water quality abstracted from groundwater capture wells downgradient of the facility. With active capture, based on the 95th percentile modelling results, groundwater at the well line may exceed water quality standards with respect to nitrate within the 30 year post-closure management period, and may exceed water quality standards for arsenic in the long-term after several hundred years. Groundwater removed from the capture wells will remain below water quality standards based on the 50th percentile modelling predictions. As noted above, modelling indicated that attenuation within the bedrock downstream of the facility was such that this localised deterioration in water quality was not sufficient to result in a breach of water quality standards at the point of discharge to the alluvial aquifer.

On the basis of the modelling undertaken, the study concluded that, given uncertainties in contaminant transport in the fractured aquifer and the exceedance of water quality standards at the 95th percentile, construction of the facility without engineered containment did not represent an acceptable design solution based on risk to the water environment. Both complete lining of the facility, and groundwater capture for 30 years were concluded to be potentially acceptable approaches in mitigating risk to the water environment. It is significant that in this case, the transient nature of a significant contaminant source in the IMWF (associated with the 'first flush' release of contaminants from the waste during initial wetting) is such that the majority of contaminant mass released to groundwater from the facility is expected to occur during operation. As a result, groundwater contamination attenuates with time following closure of the facility, making both a permanent (effectively passive) and transient (active) management solution a viable possibility at this site.

The two options were further evaluated by DPMK, and due to concerns over the ability to install and maintain the integrity of a full lining system, the groundwater capture system was selected to be carried forward in the design. An important geopolitical consideration that should be noted here is that groundwater capture systems are in use at other sites in Bulgaria, such that this is considered a proven technology in the country for this purpose.

Surface water and groundwater impact assessment undertaken at the design stage for the Krumovgrad IMWF has provided predictions regarding the influence of the facility on groundwater and surface water during operation, closure and in post-closure. However, these predictions are necessarily based on comparatively limited information that is available at the design stage. Whilst the methodology presented, 
which uses probabilistic modelling to incorporate the influence of design uncertainty, incorporates sensitivity analysis in deterministic modelling components contributing to the assessment, provides a mechanism to allow for and address uncertainty in design decisions and is considered fit for purpose, the modelling is inevitably based on a large number of assumptions. Ongoing validation and refinement of the modelling through further testing and monitoring in construction and operation remains essential to refine the closure and post-closure predictions as development of the site progresses.

\section{Conclusion}

The assessment of the risk that mine waste facilities pose to the water environment incorporates many phases of assessment and requires integration of geochemical, hydrological and hydrogeological studies, and consideration of impacts through the entire mine lifecycle. Highly flexible dynamic simulation platforms allow Monte Carlo analysis to be applied in predictive modelling of relatively complex systems and of lifecycle change, represented through analytical element models. Such models can have advantages over more rigorous numerical methods in some situations, both in aiding the understanding and communication of risk, and in supporting decision making.

In the case study presented, hydraulic modelling and geochemical and mass balance modelling undertaken in the earlier parts of the performance assessment indicated that the facility is unlikely to pose a risk to the water environment in the long-term because predictions suggest that post-closure water quality will be similar to baseline surface water quality. However, it was the release of contaminants in the 'first flush' from the deposited waste during the operational phase, and the legacy of this contamination in underlying ground, that proved to be a driver for further quantitative assessment of the impact on downgradient groundwater and surface water receptors.

Probabilistic modelling undertaken to assess contaminant transport in groundwater from the facility and impacts on groundwater and surface water during operation and closure concluded that without any form of engineered containment, the facility posed an unacceptable risk to groundwater due to the release of contaminants to ground during the operational phase. This release was predicted to continue to affect groundwater downgradient of the site for many years following closure due to the slow movement of some contaminants in the geosphere. Due to the comparatively transient nature of the source term associated with the waste materials, which geochemical assessment indicated to be primarily associated release during the initial wetting of the wastes, the modelling was able to demonstrate that both full lining of the facility, and groundwater capture for a 30 year period following closure were acceptable solutions to mitigate risks to groundwater and surface water from the site. Active groundwater management for this period captured a sufficient proportion of the released contamination to ameliorate long term risks. Facility construction and long-term integrity risks have been reduced through selection of a groundwater capture design in place of a fully lined design to mitigate risks to the water environment. This outcome may not have been achieved without an assessment methodology which permitted dynamic simulation of the source term and containment engineering evolution.

The use of a probabilistic analytical element modelling approach in the water impact assessment has allowed the consideration of uncertainty in key aspects of the groundwater system in this case study, such that ultimate decision making has been based on 'worse case' outcomes based on the available information and conservative assumptions to increase certainty and robustness of the design solution. This can be expected to reduce the risk that major changes to the design will be required as more data becomes available as operations proceed.

The assessment approach described in this paper represents a possible methodology which is able to incorporate and address uncertainty in predictive modelling at the design stage for operation and closure, and is considered extremely useful in guiding decision making at the design stage. However, the modelling is inevitably based on a large number of assumptions. Ongoing validation and refinement of the modelling through further testing and monitoring in construction and operation remains essential in this case, and for any site, to refine the closure and post-closure predictions as development of the site progresses. 


\section{Acknowledgement}

The work presented was undertaken for DPMK as part of the Krumovgrad Gold Project, the support of DPMK in guidance of the project, and for submission of this paper is gratefully acknowledged.

Geochemical testing for the Krumovgrad Project was undertaken by Eurotest Control EAD.

\section{References}

EC (European Commission) 2009, Reference Document on Best Available Techniques for Management of Tailings and Waste-Rock in Mining Activities, http://eippcb.jrc.ec.europa.eu/reference/BREF/mmr_adopted_0109.pdf

EU (European Union) 2000, Directive 2000/60/EC of the European Parliament and of the Council of 23 October 2000 establishing a framework for Community action in the field of water policy.

EU (European Union) 2006a, Directive 2006/11/EC of the European Parliament and of the Council of 15 February 2006 on pollution caused by certain dangerous substances discharged into the aquatic environment of the Community.

EU (European Union) 2006b, Directive 2006/21/EC of the European Parliament and of the Council of 15 March 2006 on the management of waste from extractive industries and amending Directive 2004/35/EC.

EU (European Union) 2006c, Directive 2006/118/EC of the European Parliament and of the Council on the protection of groundwater against pollution and deterioration, 12 December 2006.

GEO-SLOPE 2013, Geostudio 2012, September 2013 release, http://www.geo-slope.com/

Giroud, JP 2001, Evaluation of Use of Bituminous Geomembrane at the Kildare By-Pass.

Giroud, JP \& Bonaparte R 1989, 'Leakage through Liners Constructed with Geomembranes - Part I: Geomembrane Liners'. Geotextiles and Geomembranes, vol. 8, pp. 27-67.

Golder Associates 2014, Post-Closure Seepage Water Quality Predictions, Integrated Mine Waste Facility, Reference KGP100-05001000-RPT-1002_B, Lakewood, Colorado.

GoldSim Technology Group 2014, GoldSim 11.1.2, released November 2014, http://www.goldsim.com/

INAP (The International Network for Acid Prevention) 2009, Global Acid Rock Drainage Guide (GARD Guide), http://www.gardguide.com/

MEND (Mine Environment Neutral Drainage) 2009, Prediction Manual for Drainage Chemistry from Sulphidic Geologic Materials, MEND Report 1.20.1.

NGCLC (National Groundwater and Contaminated Land Centre) 1999, Guidance on Assigning Values to Uncertain Parameters in Subsurface Fate and Transport Modelling, NGCLC Report NC/99/38/3.

Parkhurst, DL \& Appelo, CAJ 2013, Description of input and examples for PHREEQC version 3-A computer program for speciation, batch-reaction, one-dimensional transport, and inverse geochemical calculations: U.S. Geological Survey Techniques and Methods, book 6, chapter A43, p. 497, http://pubs.usgs.gov/tm/06/a43/

Rushton, KR 2003, Groundwater Hydrology: Conceptual and Computational Models, Wiley, Chichester, p. 416. 